\title{
PREDAÇÃO DE SEMENTES DE ANDIROBA [Carapa guianensis Aubl. E Carapa procera DC. (Meliaceae)] POR INSETOS NA AMAZÔNIAS ${ }^{1}$
}

\author{
Adriana Araújo Pinto², Beatriz Ronchi Teles ${ }^{3}$, Norivaldo dos Anjos ${ }^{4}$ e Sheyla Regina Marques \\ Couceiro $^{5}$
}

\begin{abstract}
RESUMO - Os objetivos deste trabalho foram identificar os insetos associados à predação de sementes de Carapa guianensis e Carapa procera e avaliar o potencial de dano nas sementes por insetos e a ocorrência de estratificação vertical na predação de sementes de andiroba. O estudo foi realiado em plantios de C. guianensis e C. procera na Reserva Florestal Ducke, Manaus, Estado do Amazonas, Brasil. As coletas foram realizadas semanalmente no chão da floresta e mensalmente em três diferentes alturas (terços) da copa das árvores. Para avaliar o efeito da predação na germinação, 30 sementes não predadas e 30 sementes predadas coletadas mensalmente do chão da floresta foram colocadas para germinar por um período de um mês. Os resultados indicaram que Hypsipyla grandella e $H$. ferrealis (Lepidoptera, Pyralidae) foram as principais espécies de insetos associadas à predação das sementes de C. procera e C. guianensis, resultando em taxas de predação média de 39\% a 61,96\%, respectivamente. Observou-se estratificação vertical na predação dos frutos e sementes na copa das árvores de ambas as espécies de Carapa. A predação das sementes de C. procera e C. guianensis por Hypsipyla spp. reduziu o processo de germinação. Este estudo produziu informações sobre a associação entre C. procera e C. guianensis e as espécies de Hypsipyla.
\end{abstract}

Palavras-chave: Hypsipyla grandella; Hypsipyla ferrealis; Amazônia.

\section{SEED PREDATION OF CRABWOOD [Carapa guianensis Aubl. AND Carapa procera DC. (Meliaceae)] BY INSECTS IN AMAZON}

\begin{abstract}
The objectives of this study were to identify the insects associated to seed predation of Carapa guianensis and Carapa procera, to evaluate the seeds damage potential of these insects and the occurrence of vertical stratification in the predation of Carapa seeds. The study was carried out in C. guianensis and C. procera plantations at Reserva Florestal Ducke, Manaus, Amazonas State, Brazil. The seed samples from the ground were taken weekly, and the canopy samples were taken monthly from three different heights. To evaluate the effect of predation on germination, 30 non-predated seeds and 30 predated seeds were collected monthly from the ground at each plot, and the germination was monitored during a month. The results showed that Hypsipyla grandella and $\boldsymbol{H}$. ferrealis (Lepidoptera: Pyralidae) are the main insect species associated to seed predation in C. procera and C. guianensis, with predation mean rates of $39 \%$ to $61,96 \%$, respectively. Fruit and seed predation were observed inside the canopy vertical stratification of the two Carapa species. The seed predation in C. procera and C. guianensis by Hypsipyla spp. reduced the germination process. This study produced information on the association between C. procera and C. guianensis and the species of Hypsipyla.
\end{abstract}

Keywords: Hypsipyla grandella; Hypsipyla ferrealis; Amazonia.

\footnotetext{
${ }^{1}$ Recebido em 21.09.2012 aceito para publicação em 15.10.2013.

${ }^{2}$ EcoTec Pragas Urbanas, Brasil. E-mail: <adr.araujop@gmail.com>.

${ }^{3}$ Instituto Nacional de Pesquisas da Amazônia, Coordenação de Pesquisas em Entomologia. E-mail: <ronchi@inpa.gov.br>. ${ }^{4}$ Departamento de Biologia Animal, Manejo de Pragas Florestais, Universidade Federal de Viçosa, Casa dos Cupins/DBA/ CCB/UFV. E-mail: <nanjos@ufv.br>

${ }^{5}$ Universidade Federal do Oeste do Pará, Instituto de Ciências e Tecnologia das Águas. E-mail: <sheylacouceiro@yahoo.com.br>.
} 


\section{INTRODUÇÃO}

Em florestas tropicais, grande parte das sementes é consumida por insetos e outros predadores (JANZEN, 1971a; HOLL; LULLOW, 1997), pois representam fonte concentrada de proteínas e minerais (MATTSON, 1980). Os estudos sobre danos causados por insetos em frutos e sementes de espécies florestais têm importância crescente. Com o ataque, as sementes predadas perdem o poder germinativo, pois seus cotilédones são consumidos pelas larvas desses insetos, sendo esse um dos estágios mais críticos do ciclo de vida das plantas após a dispersão (FENNER, 1985). A principal forma de propagação das espécies florestais é através de sementes, entretanto algumas apresentam interações com insetos que se desenvolvem no interior das estruturas reprodutivas, afetando a qualidade da semente destinada à perpetuação da espécie (KUNIYOSHI, 1983).

A predação de sementes florestais por insetos ocorre em grande quantidade de famílias de plantas, principalmente por larvas de Diptera, Coleoptera e Lepidoptera (CRAWLEY, 1992). A perda de sementes antes da dispersão varia entre espécies e populações de plantas, mas frequentemente atinge mais de $90 \%$ das sementes produzidas (e.g. MATTSON, 1980; RANDALL, 1986; CRAWLEY; GILLMAN, 1989).

Carapa guianensis Aubl. (andiroba) e C. procera DC (andirobinha) (Meliaceae) são espécies nativas da Amazônia e de uso múltiplo, em que a madeira e o óleo extraído de suas sementes são os produtos mais importantes (NEVES et al., 2004). São consideradas espécies promissoras para enriquecerem capoeiras, florestas, sistemas agroflorestais e recuperação de áreas úmidas degradadas (FERRAZ et al., 2002). Além disso, a andiroba possui potencial promissor para se aclimatar às mudanças ambientais previstas em futuro próximo para a maior parte da região amazônica (CAMARGO; MARENCO, 2012). No Brasil, as duas espécies ocorrem em três tipos de hábitat: terra firme, igapó e várzea (LEITE, 1997; FERRAZ et al., 2003). Apresentam maiores densidades em áreas ocasionalmente alagadas (LEITE, 1997; BOUFLEUER, 2004; PLOWDEN, 2004; KLIMAS, 2006).

Existe a presença de insetos em estruturas reprodutivas de muitas espécies florestais, embora não haja estudos sobre a taxa de predação e quais insetos estão associados a frutos e sementes de $C$. guianensis e $C$. procera, sendo citadas na literatura apenas espécies de lepidópteros que ocorrem em suas sementes (BECKER, 1971; FERRAZ et al., 2002).
O primeiro registro foi de Hypsipyla grandella Zeller (Pyralidae) como praga da silvicultura (MONTE, 1933). Os microlepidópteros que vivem em essências florestais, como Stryphnodendron obovatum Benth (Leguminosae), Cassia fistula L. (Leguminosae) e Carapa guianensis Aubl. (Meliaceae) foram relatados por Becker (1971). Adultos de Hypsipyla ferrealis Hampson (Pyralidae) foram registrados em sementes de C. guianensis na Costa Rica (BECKER, 1973a). Descrições sobre a emergência e acasalamento da brocado-ponteiro (H. grandella) foram feitas por Becker (1973b).

Este trabalho teve como objetivos identificar os insetos associados à predação de sementes de Carapa guianensis e C. procera e avaliar o potencial de dano nas sementes por esses insetos, bem como a ocorrência de estratificação vertical na predação de sementes dessas duas espécies de andiroba na Reserva Florestal Ducke, Manaus, Estado do Amazonas, Brasil.

\section{MATERIAL E MÉTODOS}

\section{1. Área de estudo}

O estudo foi realizado na Reserva Florestal Ducke (km 26 da rodovia AM-010), área pertencente ao Instituto Nacional de Pesquisas da Amazônia (INPA), situada a Noroeste da cidade de Manaus, entre os paralelos $02^{\circ} 55^{\prime}-03^{\circ} 01^{\prime}$ 'S e 595' - 5959' W. A reserva abrange uma área de $100 \mathrm{~km}^{2}$.

Segundo a classificação de Köppen, o clima da região é do tipo Afi (A - clima tropical), com chuvas concentradas nos meses de março e abril, sendo de julho a setembro os meses mais secos do ano. A temperatura média anual situa-se em torno de $26,7^{\circ} \mathrm{C}$, sendo a precipitação média anual de 2.105 mm (BRINKMANN et al., 1971).

A reserva pode ser definida como uma floresta do tipo tropical úmida, possuindo a denominação “TerraFirme”, o qual se aplica a florestas que não são sazonalmente inundadas pela cheia dos rios, diferenciadas, assim, das florestas de várzea e igapó (RIBEIRO et al., 1999).

Nos plantios de C. guianensis e C. procera na Reserva Florestal Ducke, foram definidas cinco parcelas, sendo as parcelas 1 e 2 de C. procera; parcelas 3 e 5 de C. guianensis; e a parcela 4, mista das duas espécies. 
Cada parcela continha 12 árvores, sendo na parcela mista essas 12 árvores divididas em seis plantas de cada espécie. As parcelas 1, 2 e 3 situavam-se próximas à Sede de Reserva Florestal Ducke e as parcelas 4 e 5, próximas à Estação Meteorológica da Reserva. No total, 30 árvores de cada espécie foram marcadas, numeradas e dimensionadas quanto ao diâmetro à altura do peito (DAP).

\subsection{Coleta de sementes de andiroba}

Visitas a campo foram realizadas semanalmente de fevereiro a junho de 2006, totalizando 18 coletas em cada parcela, em que foram coletadas todas as sementes e frutos no chão, com e sem sintomas de ataque de insetos.

Os frutos coletados foram separados por espécie e abertos para quantificação e separação das sementes predadas e não predadas, sendo considerados predados os frutos que apresentavam sinais de perfurações e, ou, com sementes danificadas por insetos.

As sementes predadas foram acondicionadas, individualmente, em recipientes plásticos cobertos com filme de PVC e mantidas em condições de laboratório (temperatura de $25{ }^{\circ} \mathrm{C} \pm 2{ }^{\circ} \mathrm{C}$ e umidade relativa do ar de $70 \% \pm 10 \%)$. Tais recipientes plásticos foram identificados e monitorados diariamente para a contagem de adultos emergidos das sementes. Os exemplares de insetos coletados foram preservados em álcool e, ou, montados em alfinetes, identificados e enviados a especialista para confirmação específica.

Para os estudos de estratificação vertical foram realizados sorteios mensais (com uso de números aleatórios) de três árvores de cada parcela de Carapa, para amostragem. De cada árvore foram coletados três frutos em cada um dos três diferentes terços da copa: inferior (altura 4 a $7 \mathrm{~m}$ ), médio (10 a $13 \mathrm{~m}$ ) e superior (acima de $16 \mathrm{~m}$ ), totalizando nove frutos por árvore e 27 por parcela, à exceção da parcela mista, de onde foram coletados 54 frutos: 27 de C. guianensis e 27 de C. procera.

A metodologia utilizada na colheita foi a de escalada nas árvores através de esporões e poda de galhos que apresentavam frutificações e, ou, ainda, da derrubada direta dos frutos. Para determinar os terços, utilizou-se como indicador uma haste de alumínio dividida em partes, utilizada para podar os galhos com as frutificações.
Para os estudos de germinação, as sementes das cinco parcelas foram separadas em predadas e não predadas e a seguir quantificadas, sendo utilizadas amostras de 30 sementes predadas e 30 sementes não predadas de cada parcela a cada mês.

A espessura do envoltório das sementes de $C$. guianensis e C. procera pode retardar o tempo no processo de germinação. Por isso, Ferraz et al. (2002) recomendaram a remoção do envoltório com uma leve secagem à sombra da semente por dois dias, facilitando, assim, o desprendimento da casca pelo trato manual, acelerando, com isso, o processo de germinação das sementes de ambas as espécies. Assim, após a remoção do envoltório, as sementes foram colocadas durante $12 \mathrm{~h}$, em recipientes com água e, posteriormente, semeadas a $2 \mathrm{~cm}$ de profundidade em bandejas de plástico $(40 \times 60 \times 10 \mathrm{~cm})$ com substrato constituído de areia branca lavada. Os experimentos de germinação foram feitos a pleno sol na área externa do INPA e as bandejas, irrigadas diariamente. Após 30 dias da semeadura de cada amostra (contados a partir do mês em que foram colocadas nas bandejas), foi efetuada a contagem do número de sementes germinadas, considerando-se como tais aquelas que deram origem a plântulas com suas estruturas essenciais bem desenvolvidas e sadias.

\subsection{Análises dos dados}

A taxa de predação (Tp) das sementes foi calculada com base na relação entre o número de sementes predadas (Np) e o total de sementes coletadas (Ns) vezes 100, em cada amostragem. Esse cálculo foi realizado para cada uma das espécies de Carapa estudadas, bem como para cada parcela investigada, através da fórmula:

$$
\mathrm{Tp}=\frac{\mathrm{Np}}{\mathrm{Ns}} \times 100
$$

A taxa de predação entre as espécies de Carapa foi comparada através do teste de Mann-Whitney (teste U) (ZAR, 1996). Esse teste foi, também, utilizado para comparar a abundância das duas espécies de insetos mais frequentes nas sementes de C. guianensis e C. procera.

O teste de Kruskall-Wallis foi utilizado para comparar a taxa de predação entre as parcelas amostradas. Esse teste também foi aplicado para avaliar a existência de diferenças na estratificação vertical da predação de frutos e respectivas sementes, entre os terços das copas de C. guianensis e C. procera amostradas em cada parcela.

Revista Árvore, Viçosa-MG, v.37, n.6, p.1115-1123, 2013 
Em caso de significância, o teste de Tukey foi utilizado a posteriori para separar as médias diferentes. Os mesmos testes foram aplicados para avaliar se existe diferença na taxa de predação, por terço, causada pelas duas espécies mais abundantes de insetos predadores das sementes de C. guianensis e C. procera.

O nível de significância adotado nesses testes estatísticos foi $\mathrm{p}<0,05$ e a medida de variação utilizada, o erro-padrão, devido à não normalidade dos dados.

A taxa de germinação das sementes predadas foi calculada com base na quantidade percentual de sementes germinadas em relação ao total de sementes predadas de C. guianensis e C. procera. Da mesma forma, a taxa de germinação de sementes não predadas foi calculada com base na quantidade percentual de sementes germinadas em relação ao total de não predadas.

A análise de variância one-way foi utilizada para verificar possíveis diferenças das taxas de germinação entre as parcelas. Os dados foram transformados em raiz quadrada antes das análises. As taxas de germinação de sementes predadas e sementes não predadas foram comparadas pelo teste de Mann-Whitney (teste U) em cada parcela utilizada.

\section{RESULTADOS}

\subsection{Insetos associados à predação das sementes de andiroba}

Foi coletado um total de 20.617 sementes de $C$. guianensis e C. procera, das quais $55,47 \%$ estavam predadas por insetos. Delas, 9.445 eram sementes de C. procera e 11.172 de C. guianensis. A taxa de predação foi de $49,64 \%$ nas sementes de C. procera e $60,39 \%$ nas de C. guianensis, diferindo significativamente entre as duas espécies de Carapa $(\mathrm{U}=24640,5 ; \mathrm{p}=0,002)$. Em ambas as espécies de Carapa, a predação foi associada à presença de Hypsipyla grandella e, principalmente, de $H$. ferrealis (Figura 1).

Com relação à taxa de predação entre as parcelas, a parcela 2 (C. procera) teve percentual menor em relação às outras parcelas, que não apresentaram diferenças significativas na taxa de predação das sementes ( $\mathrm{P}>0,0001)$.

Foram registrados também os insetos Corcyra cephalonica Stainton (Pyralidae, Lepidoptera) e Ptecticus testaceus Fabricius (Stratiomyidae, Diptera), além de espécimes de Curculionidae, Nitidulidae e Tenebrionidae (Coleoptera). Esses insetos foram encontrados somente nas parcelas 1, 2 e 3 .

\subsection{Avaliação da estratificação vertical na predação das sementes}

Um total de 486 frutos foi coletado nas árvores selecionadas nas cinco parcelas de Carapa. Desse total, 229 frutos (106 de C. procera e 123 C. guianensis) apresentaram marcas de ataque de insetos, o que representa $47,11 \%$ dos frutos coletados $(21,81 \%$ de C. procera e $25,30 \%$ de C. guianensis).

A porcentagem de predação dos frutos foi de $66,66 \%$ no terço inferior, $54,93 \%$ no terço médio e $19,75 \%$ no terço superior. Da mesma forma, as porcentagens médias de sementes predadas retiradas dos frutos sugerem diferenças significativas entre os três terços das copas das árvores (Figura 2). Os resultados do teste de Kruskal-Wallis foram $\mathrm{H}=$ 20,09963, $\mathrm{p}<0,0001$ na parcela $1 ; \mathrm{H}=14,23863, \mathrm{p}<0,008$ na parcela 2; $\mathrm{H}=30,57822$, $\mathrm{p}<0,0001$ na parcela 3 ; $\mathrm{H}=32,66866, \mathrm{p}<0,00001$ na parcela $4 \mathrm{em}$ C. procera; $\mathrm{H}=5,845416, \mathrm{p}<0,0538$ na parcela 4 em C. guianensis; e $\mathrm{H}=7,417446, \mathrm{p}<0,0245$ na parcela 5 .

A presença de estratificação vertical na predação nas sementes dos frutos coletados nos três terços de C. guianensis e C. procera indica maiores níveis de predação nos terços inferiores em todas as parcelas avaliadas.

Em relação aos insetos predando os frutos e suas sementes, $H$. ferrealis foi a espécie mais coletada nos três terços amostrados, desde o terço inferior até o superior das árvores (Figura 3). H. grandella foi coletada somente no terço inferior em todas as parcelas.

Os resultados sugerem que os frutos e respectivas sementes localizados no terço inferior das copas das árvores de C. guianensis e C. procera são o principal alvo de predação por insetos.

\subsection{Avaliação da predação sobre a germinação das sementes de andiroba}

A taxa de germinação das sementes predadas variou de $8,88 \%$ a 17,77\% (Figura 5). H. ferrealis e $H$. grandella são as principais espécies a interferir na germinação de tais sementes, resultado esse observado em todas 
as parcelas com a redução na taxa de germinação das sementes predadas em relação às não predadas.

Os resultados na taxa de germinação de sementes não predadas (Figura 4) das parcelas de C. guianensis e C. procera corroboram os resultados de Ferraz et
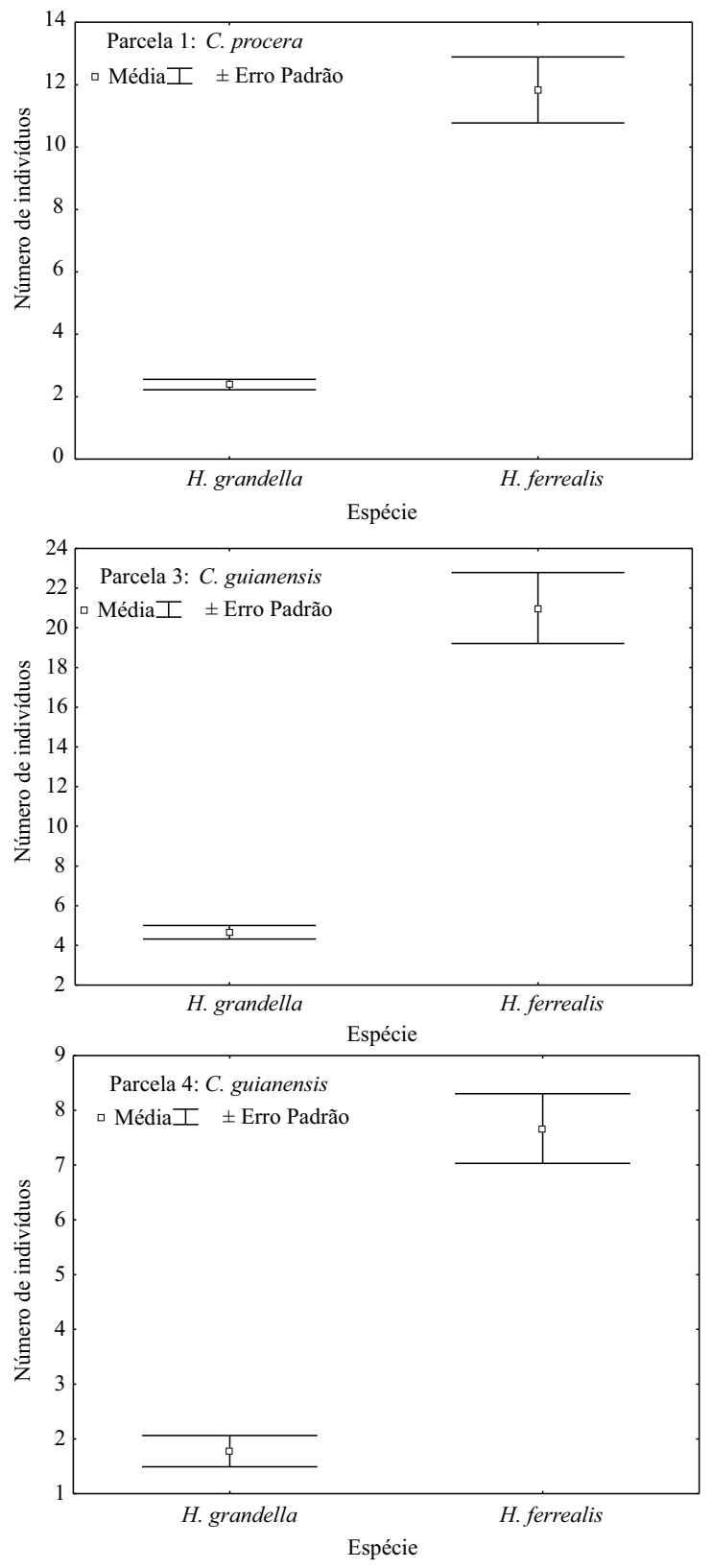

al. (2002), que obtiveram taxa de germinação de $90 \%$ em C. procera e $70 \%$ em C. guianensis.

Não foram observadas diferenças significativas entre as parcelas de C. procera e C. guianensis (Figura 5).
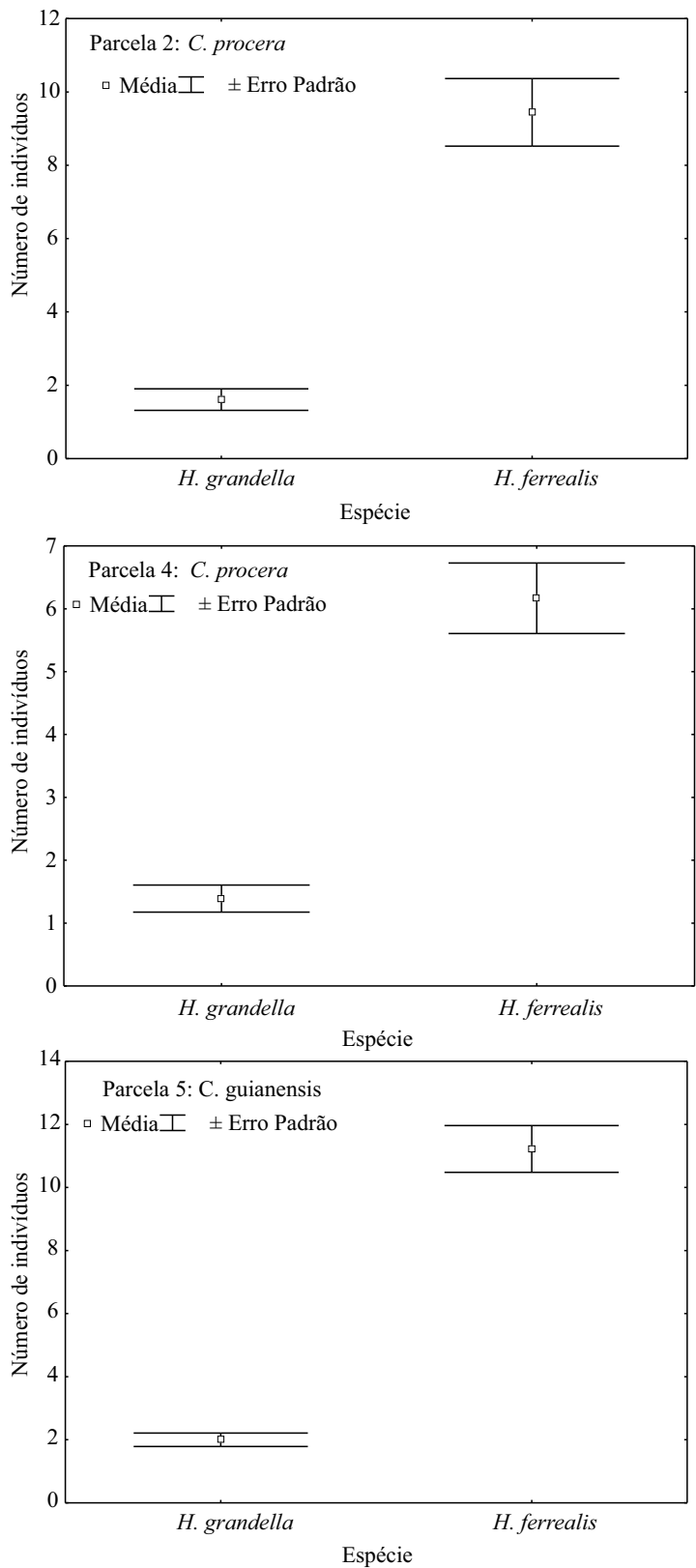

Figura 1 - Média de Hypsipyla grandella e H. ferrealis nas parcelas avaliadas na Reserva Florestal Ducke, Manaus, Amazonas. Figure 1 - Average of Hypsipyla grandella and $\mathbf{H}$. ferrealis in the plots evaluated at Ducke Forest Reserve, Manaus, Amazonas State. 


\section{DISCUSSÃO}

As altas taxas de predação verificadas neste estudo sugerem que as sementes das espécies de Carapa são recursos muito procurados por $H$. grandella e, principalmente, por $H$. ferrealis, durante o período de frutificação edispersão das sementes. Na Costa Rica, Santander e Albertin (1978) relataram 36\% de danos provocados por larvas de $H$. ferrealis em sementes de C. guianensis.
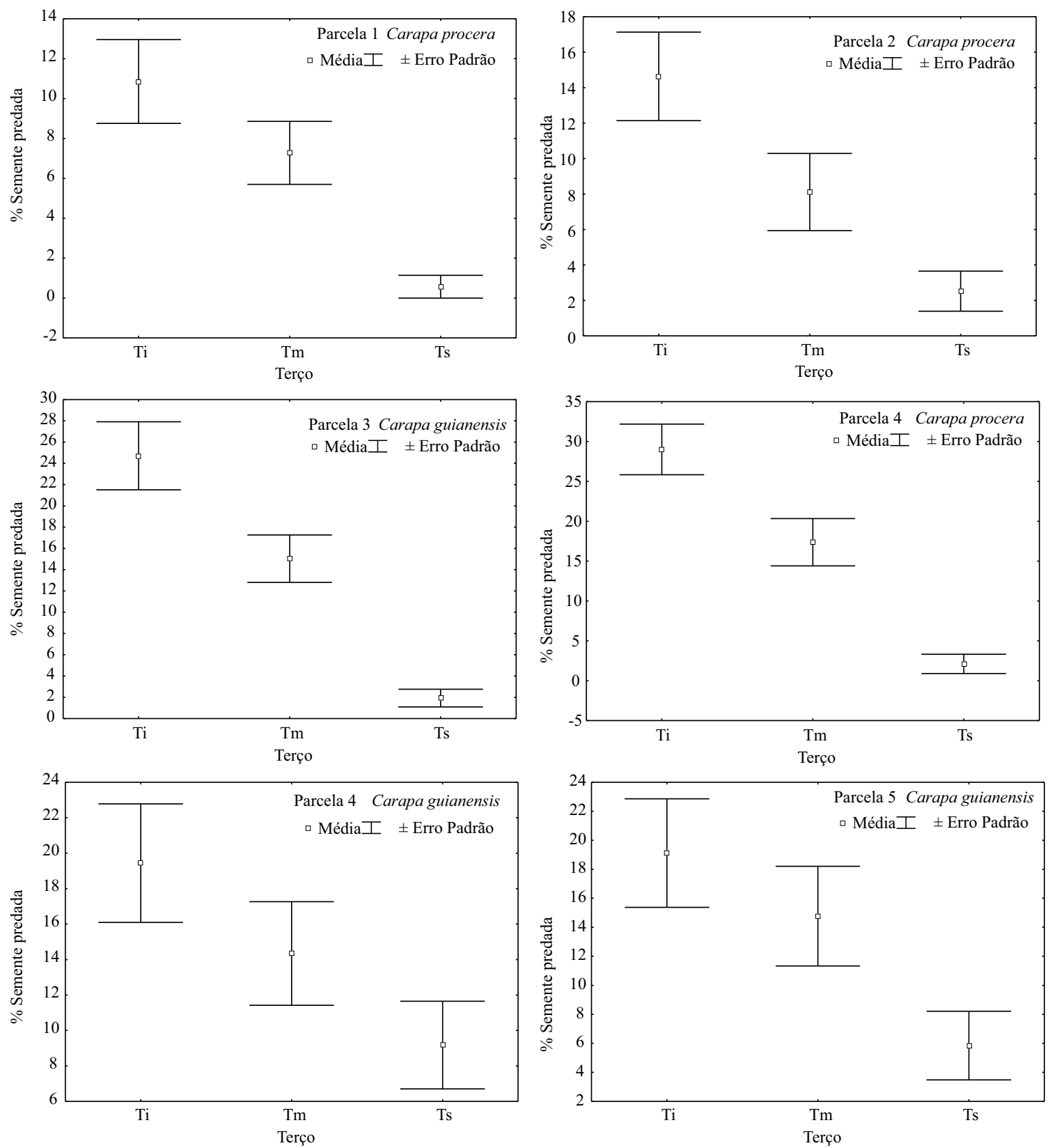

Figura 2 - Predação de sementes dos frutos de Carapa guianensis e C. procera por insetos no terço inferior (Ti), no terço médio (Tm) e no terço superior (Ts) da planta superior na Reserva Florestal Ducke, Manaus, Amazonas.

Figure 2 - Seed predation in fruits of Carapa guianensis and C. procera by insects in the lower third (Ti), middle third (Tm) and upper third (Ts) in plants of Ducke Forest Reserve, Manaus, Amazonas State.

Revista Árvore, Viçosa-MG, v.37, n.6, p.1115-1123, 2013 


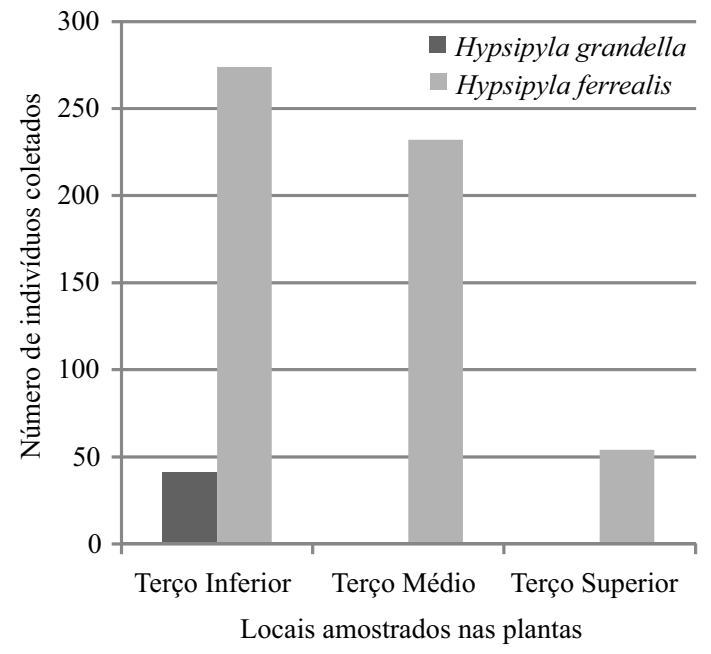

Figura 3 - Número de indivíduos de Hypsipyla grandella e de $H$. ferrealis coletadas nos frutos/sementes dos terços inferior, médio e superior de Carapa guianensis e de C. procera na Reserva Florestal Ducke, Manaus, Amazonas.

Figure 3 - Number of Hypsipyla grandella and Hypsipyla ferrealis individuals collected in fruits / seeds of lower, middle and upper Carapa guianensis and C. procera at Ducke Forest Reserve, Manaus, Amazonas State.

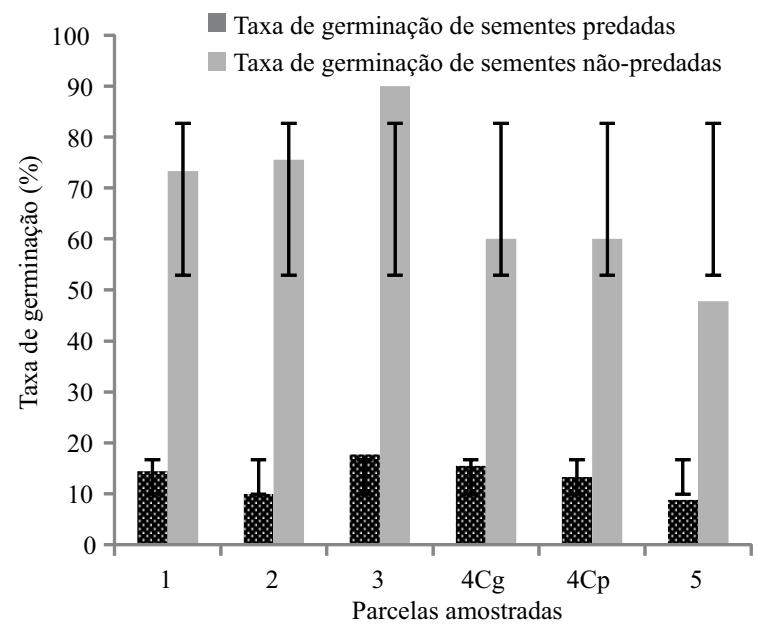

Figura 4 - Taxa de germinação das sementes predadas de Carapa guianensis e de C. procera por parcela na Reserva Florestal Ducke, Manaus, Amazonas (C.p = Carapa procera -1 , 2 e 4 C.g = Carapa guianensis - 3, 4 e 5).

Figure 4-Germination rate of Carapa guianensis and $\boldsymbol{C}$. procera predated seeds per plot at Ducke Forest Reserve, Manaus, Amazonas State (C.p = Carapa procera -1, 2 and 4 C.g = Carapa guianensis $-3,4$ and 5$)$.
As perdas causadas por $H$. ferrealis e $H$. grandella indicaram o efeito da predação por esses insetos, ocasionando a destruição das sementes e frutos durante todo o período de frutificação na Reserva Florestal Ducke, o que atesta que essas pragas são limitantes para a cultura de C. guianensis e C. procera, destruindo frutos e sementes no campo.

A alta predação que sofrem as sementes de $C$. guianensis e C. procera, aliada às irregularidades na produção de frutos da espécie, parece ser importante no ciclo de vida dessa espécie.

A porcentagem de predação dos frutos foi menor no terço superior. Verificou-se redução na porcentagem de frutos predados entre os terços, ou seja, as taxas de ataques diminuíram com o aumento da altura, o que pode significar que no dossel, onde a disponibilidade de frutos é maior que no subdossel, os insetos predadores não conseguem aumentar sua abundância de maneira rápida bastante para explorar a quantidade maior desse recurso (BEGON et al., 1996). Ainda, de acordo com Janzen (1971b), algumas espécies florestais podem apresentar eventos de frutificação alternados durante o ano, e o volume de frutos produzidos pode superar

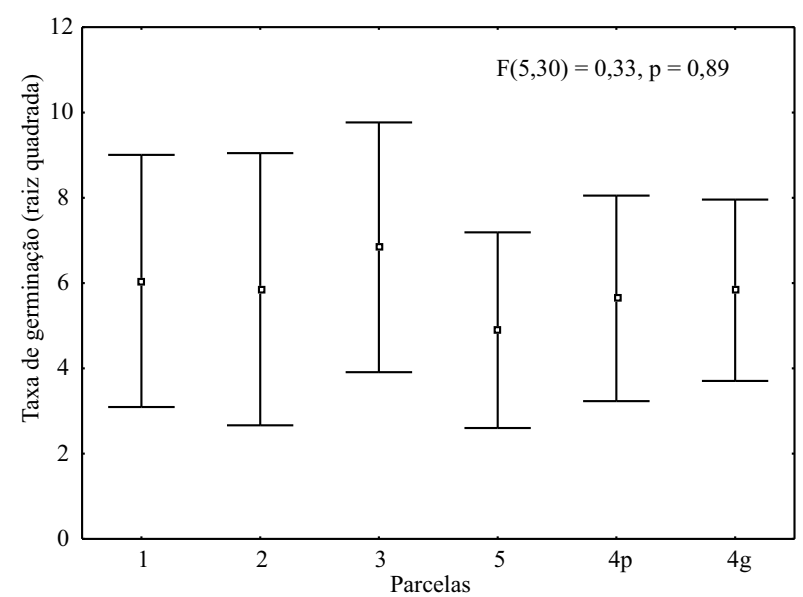

Figura 5 - Comparação das médias da taxa de germinação entre as parcelas amostradas: C. procera (1 e 2), C. guianensis (3 e 5) e parcela mista: C. procera (4p) e C. guianensis (4g). Barras representam desvio-padrão.

Figure 5 - Comparison of mean germination rate among the sampled plots: $\boldsymbol{C}$. procera (1 and 2), C. guianensis (3 and 5) and mixed plot: C. procera (4p) and C. guianensis (4g). Bars represent standard deviation.

Revista Árvore, Viçosa-MG, v.37, n.6, p.1115-1123, 2013 
a habilidade de predação dos insetos que sobreviveram a esse período, alternado em cada evento de frutificação.

As diferenças no número de indivíduos de $H$. ferrealis e $H$. grandella observadas predando frutos e, ou, sementes de C. guianensis e C. procera nos terços podem estar relacionadas com a capacidade de voo de cada espécie. O ataque de $H$. grandella em brotos apicais de Meliaceae tende a ser mais pronunciado durante os primeiros três a seis anos e altura variando de 2 a $8 \mathrm{~m}$, sendo este o estágio da planta mais suscetível ao ataque (MAYHEW; NEWTON, 1998). Logo, a dinâmica de voo de $H$. grandella somente até o terço inferior, com altura variando de 4 a $7 \mathrm{~m}$ de $C$. guianensis e $C$. procera, pode estar moldando os padrões de distribuição da abundância de Pyralidae nos frutos das duas espécies da Reserva Florestal Ducke.

A predação de sementes exerceu papel importante no potencial biótico de C. guianensis e C. procera, pois reduziu o percentual de germinação de sementes disponíveis para a produção de mudas em viveiros. Mesmo as sementes predadas por $H$. grandella e $H$. ferrealis que germinaram formarão, provavelmente, mudas pouco vigorosas, comprometendo seu desenvolvimento fisiológico.

Considerando a existência de outros fatores que impedem sua germinação, como agentes patogênicos (fungos) e condições desfavoráveis do ambiente (variações climáticas) (FERREIRA, 1989), a predação das sementes por insetos interfere na sua germinação, influenciando no potencial reprodutivo dessas espécies.

Neste estudo foram registrados, pela primeira vez no Brasil, H. grandella associada à predação de sementes de $C$. procera. Também, foi registrada a primeira ocorrência de Corcyra cephalonica em sementes de C. guianensis e Ptecticus testaceus em sementes de C. procera e C. guianensis.

\section{CONCLUSÕES}

Hypsipyla ferrealis Hampson e H. grandella Zeller foram os insetos mais importantes na predação de sementes de Carapa guianensis e C. procera na Reserva Florestal Ducke, em Manaus, Amazonas.

Hypsipyla ferrealis ocorreu em toda a copa, sendo mais abundante no terço inferior. Hypsipyla grandella foi encontrada somente no terço inferior.
A predação de sementes por $H$. grandella e $H$. ferrealis reduziu o percentual de germinação de sementes.

\section{AGRADECIMENTOS}

Ao Dr. Vitor O. Becker, pela identificação dos Pyralidae; e ao M. Sc. Fábio Siqueira P. Godoi, pela identificação dos Stratiomyidae.

\section{REFERÊNCIAS}

BECKER, V. O. Microlepdópteros que vivem nas essencias florestais do Brasi. I. Hypsipyla ferrealis (Hampson) (Lepidoptera, Pyralidae, Phycitinae), broca da andiroba, Carapa guianensis Aubl. (Meliaceae). Floresta, v.3, n.1, p.85-90, 1971.

BECKER, V. O. Estudios sobre el barrenador Hypsipyla grandella (Zeller) (Lep., Pyralidae): XVI. Observaciones sobre la biología de $H$. ferrealis (Hampson), Una Especie Afín., Turrialba, v.23, n.2, p.155-161, 1973a.

BECKER, V. O. Studies on the shootborer Hypsipyla grandella (Zeller) (Lep. Pyralidae). XX. Observations on emergence and mating of adults incaptivity. Turrialba, v.23, n.3, p.352-356. 1973b.

BEGON, M.; HARPER, J. L.; TOWNSEND, C. R. Ecology: individuals, populations and communities. 3.ed. London: Blackwell Science, 1996.

BOUfleuer, N. T. Aspectos ecológicos da andiroba (Carapa guianensis Aublet. Meliaceae) subsidios para o manejo. 2004. 90f. Dissertação (Mestrado em Ecologia e Manejo de Recursos Naturais) - Universidade Federal do Acre, Rio Branco, 2004.

BRINKMANN, W. L.; WEINMAN, M. N. G.; RIBEIRO, J. E. L. S. Air temperatures in Central Amazonica. 1. The daily record of air temperatures in a secondary florest near Manaus under cold front conditions. Acta Amazonica, v.1, n.1, p.75-76, 1971.

CAMARGO, M. A. B.; MARENCO, R. A. Growth, leaf and stomatal traits of crabwood (Carapa guianensis Aubl.) in central Amazonia. Revista Árvore, v.36, n.1, p.07-16, 2012. 
CRAWLEY, M. J. Seed predators and plant population dynamics. In: FENNER, M. (Ed): Seeds: the ecology of regeneration in the plant communities. Wallingford: CAB International, 1992. p.157-191.

CRAWLEY, M. J.; GILLMAN, M. P. Population dynamics of cinnabar moth and ragwort in grassland. Journal of Animal Ecology, v.58, n.3, p.1035-1050, 1989.

FENNER, M. Seed ecology. New York: Chapman e Hall, 1985. 151p.

FERRAZ, I. D. K.; CAMARGO, J. L. C.; SAMPAIO, P. T. B. Sementes e plântulas de andiroba (Carapa guianensis, Aubl. e Carapa procera DC.): aspectos botânicos, ecológicos e tecnológicos. Acta Amazonica, v.32, n.4, p.647-661, 2002.

FERRAZ, I. D. K.; CAMARGO, J. L. C.; SAMPAIO, P. T. B. Andiroba (Carapa guianensis Aubl.; Carapa procera, D.C) Meliaceae. Manaus: INPA, 2003. 6p. (Manual de sementes da Amazônia, 1)

FERREIRA, F. A. Patologia florestal; principais doenças florestais no Brasil. Viçosa, MG: Sociedade de Investigações Florestais, 1989. 570p.

HOLL, K. D.; LULLOW, M. E. Effects of species, habitat and distance from edge on post-dispersal seed predation in a tropical rainforest.

Biotropica, v.29, n.4, p.459-468, 1997.

JANZEN, D. H. Escape of Cassia grandis L. beans from predators in time and space. Ecology, v.52, n.6, p.964-979, 1971a.

JANZEN, D. H. Seed predation by animals. Annual Review of Ecology and Systematics, v.2, p.465-492, 1971 b.

KLIMAS, C. A. Ecological review and demographic study of Carapa guianensis. 2006. 65f. Dissertação (Mestrado em Engenharia Florestal) - Universidade da Flórida, Gainesville, 2006.

KUNIYOSHI, Y. S. Morfologia da semente e da germinação de 25 espécies arbóreas de uma floresta com araucária. 1983. 233f. Dissertação (Mestrado em Ciências Florestais) Curitiba - Universidade Federal do Paraná, 1983. 233p.

\author{
LEITE, A. M. C. Ecologia de Carapa \\ guianensis Aublet. (Meliaceae) \\ “andiroba”, 1997. 181f. Tese (Doutorado em \\ Biologia Ambiental) - Universidade Federal do \\ Pará/Museu Paraense Emilio Goeldi, Belém, \\ 1997.
}

MATTSON JR, W. J. Herbivory in relation to plant nitrogen content. Annual Review of Ecology and Systematics, v.11, p.119-161, 1980.

MAYHEW, J. E.; NEWTON, A. C. The silviculture of Mahogany. London: CABI Publishing, 1998. 226p.

MONTE, O. Hypsipyla grandella Zeller, uma praga da silvicultura (Lepidoptera: Phycitidae). Revista de Entomologia, v.3, p.281-285, 1933.

NEVES, O. S. C. et al. Crescimento, produção de matéria seca e acúmulo de $\mathrm{N}, \mathrm{P}, \mathrm{K}, \mathrm{Ca}, \mathrm{Mg}$ e $\mathrm{S}$ na parte aérea de mudas de andiroba (Carapa guianensis Aubl.) cultivadas em solo de várzea, em função de diferentes doses de fósforo.

Revista Árvore, v.28, n.3, p.343-349, 2004.

PLOWDEN, C. The Ecology and harvest of andiroba seeds for oil production in the Brazilian Amazon. Conservation \& Society, v.2, n.2, p.251-270, 2004.

RANDALL, M. G. M. The predation of predispersed Juncus squarrosus seeds by Coleophora alticolella (Lepidoptera) larvae over a range of altitudes in northern England. Oecologia, v.69, n.3, p.460-465, 1986.

RIBEIRO, J. E. L. S. et al. Flora da Reserva Ducke. Guia de identificação das plantas vasculares de uma floresta de terra-firme na Amazônia Central. Manaus: INPA, 1999. 799p.

SANTANDER, C.; ALBERTIN, W. Carapa Guianensis Aubl. Possible alternativa para el problema del barrenador de las Meliaceae de los Trópicos. Turrialba, v.28, n.3, p.179-186, 1978.

ZAR, J. R. Biostatistical analysis. New Jersey: Prentice Hall, 1996. 662p.

Revista Árvore, Viçosa-MG, v.37, n.6, p.1115-1123, 2013 
